\title{
A IMPORTÂNCIA DO JAZZ PARA A BATERIA BRASILEIRA
}

\section{ENSAIO TEÓRICO}

ROCHA, Luiz Renato da Silva ${ }^{1}$

ROCHA, Roger da Silva ${ }^{2}$

ROCHA, Rafael da Silva ${ }^{3}$

ROCHA, Luiz Renato da Silva. ROCHA, Roger da Silva. ROCHA, Rafael da Silva. A importância do jazz para a bateria brasileira. Revista Científica Multidisciplinar Núcleo do Conhecimento. Ano 05, Ed. 10, Vol. 04, pp. 52-64. Outubro de 2020. ISSN: 2448-0959, Link de acesso: https://www.nucleodoconhecimento.com.br/arte/importancia-do-jazz

\section{RESUMO}

Este trabalho terá como objetivo analisar como o jazz, estilo musical surgido em 1890, foi e ainda é uma importante influência para a bateria brasileira nos aspectos musicais técnicos, conceituais e melódicos, características essas ligadas ao conceito musical em que estava inserido. Esse estilo musical influenciou diversos outros segmentos da música mundial, além de buscar por qual razão se deu essa influência, desde a trajetória da criação do instrumento até os dias atuais a partir do levantamento de contextos históricos, passando por várias gerações de bateristas que deixaram um legado do estilo jazzístico até o brasileiro, se fazendo necessário destacar todo o caminho percorrido por esse instrumento popular denominado bateria ou drums set. Como instrumento metodológico, será feito um levantamento histórico e bibliográfico onde será analisado como a rápida evolução desse instrumento foi influenciada por estilos de música distintos em cada período, por cada compositor, instrumentista ou

\footnotetext{
${ }^{1}$ Especialização em Pós Graduação em Educação Musical. Graduação em Música.

2 Graduando em Música.

${ }^{3}$ Pós graduação em Educação Musical.
} 
inventor que precisasse daquela estrutura sonora que hoje a bateria nos proporciona, e na viabilidade com a redução de integrantes no instrumento que deixou de ser composta por várias partes fracionadas para hoje estar resumida em um único instrumento.

Palavras-chave: bateria, música, jazz, samba, bossa-nova.

\section{INTRODUÇÃO}

Segundo Paiva (2001), no século XX, foi criado a bateria, que em poucos anos iniciou e se expandiu de forma rápida no contexto musical agrupando aproximadamente três percussionistas em cada banda e orquestra, e no decorrer da sua invenção, em 1907 aproximadamente, foi desenvolvido pedal de bumbo e caixa, fazendo com que apenas um baterista toque o que seria para três. Segundo Maley (2000) A bateria começou a se desenvolver na década de 1890 por vários motivos: a popularidade da música de John Philip Sousa, a tendência dos produtores musicais de contratarem alguns bateristas, o espaço dos percussionistas na orquestra Insuficiência e o surgimento de orquestras músicos urbanos, especialmente músicos urbanos de New Orleans.

Ao contrário do que muitas pessoas acreditam, William Ludwig não foi o inventor do pedal, mas foi ele quem desenvolveu o primeiro modelo prático em 1910 (CANGANY, 1996; MALEY, 2000). Dee Dee Chandler (Dee Dee Chandler) é geralmente considerado o primeiro a usar os pedais no final da década de 1880 e início da década de 1890 (MALEY, 2000). Assim que o pedal aparece, a bateria começa a se desenvolver. Outra invenção que tornou possível o surgimento da bateria foi a estante de caixa. Até 1899, Lidi projetava esse tipo de suporte, os bateristas usavam cadeiras ou cintos para pendurar o tambor nos ombros (CANGANY, 1996).

Vale destacar que na linguagem brasileira da bateria, deve-se muito ao samba-jazz dos anos 1950 e aos músicos que fizeram esse período marcante, conduzindo o samba com a clave no prato e o hi-hat dando um colorido no contra-tempo e afins. Além das acentuações características, destaca-se também os tipos de peças e baquetas utilizados para reverberar aquele determinado som. 
Esta é a geração do samba jazz: Dom um Romão (1925 - 2005), Edson Machado (1934 - 1990), Milton Banana (1935 - 1999), Wilson das Neves (1936 - 2017), Rubinho Barsotti (1932), Hélcio Milito (1931 - 2014) e Hércules (1938).

Por isso procuramos entender como a bateria brasileira tem se comportado ao longo dos anos, influenciada pela chegada do jazz aos Estados Unidos. Desde então, com o avanço da bateria brasileira, mais precisamente o samba jazz, se tornou uma das primeiras influências dentro do contexto jazzístico.

\section{DESENVOLVIMENTO}

\subsection{BREVE HISTÓRICO DO JAZZ}

O desenvolvimento do jazz de Nova Orleans pode ser compreendido a partir da história e da cultura do período colonial. New Orleans foi fundada em 1718 como parte da colônia da Louisiana Francesa que em 1763 teve seus territórios cedidos para Espanha, mas foram devolvidos à França em 1803 e logo depois vendeu a colônia aos Estados Unidos na compra da Louisiana.

Em Nova Orleans, a cultura crioula era católica e de língua francesa. Já a cultura dos não protestantes era de língua inglesa, ao contrário da cultura dos americanos mais jovens. As pessoas tinham maior liberdade em suas opiniões sobre a vida e sua apreciação da comida, vinho, música e dança. Os festivais eram realizados frequentemente. Segundo relatos, William Clayburn, o primeiro governador da Louisiana nomeado pelos americanos, comentou que os residentes de Nova Orleans não podiam governar porque se concentravam na dança.

Não apenas a Europa, mas a África também enriqueceu a cultura colonial. Já em 1721 , os escravos da África Ocidental respondiam por $30 \%$ da população de Nova Orleans. No final de 1700 , a população livre e escrava de ascendência africana representava mais da metade da população da cidade. Muitas pessoas chegaram ao Mar do Caribe, trazendo consigo as tradições culturais das Índias Ocidentais. 
Depois de comprar a Louisiana, anglo-americanos e afro-americanos de língua inglesa invadiram Nova Orleans. Em parte, devido ao atrito cultural, esses novos imigrantes começaram a se estabelecer na Canal Street e no já lotado Upper French Quarter (Vieux Carré). Esses assentamentos expandiram o alcance da cidade e criaram áreas residenciais americanas separadas dos antigos centros crioulos. Os negros americanos invadiram áreas residenciais primeiro como escravos e depois como homens livres, trazendo elementos do estilo blues e da espiritualidade das danças com origens rurais para integrar a música de Nova Orleans.

No século XIX, a diversidade étnica aumentou ainda mais. Antes da Guerra Civil, muitos imigrantes alemães e irlandeses chegaram e, desde então, o número de imigrantes italianos aumentou. Os novos imigrantes europeus estão concentrados em Nova Orleans, no sul. A rica integração da cultura de Nova Orleans trouxe consideráveis intercâmbios culturais. Um dos primeiros exemplos é a comunidade crioula relativamente grande e incolor da cidade. Os crioulos de cor são pessoas de ascendência mista africana e europeia, geralmente artesãos e empresários bemeducados. Muitos músicos crioulos foram educados por franceses e tocavam nas melhores bandas onde ficaram conhecidos por sua habilidade e disciplina.

Apesar dos preconceitos tradicionais, muitas pessoas de diferentes culturas e raças por não ter escolhas vivem juntas, o que promove a interação cultural. Por exemplo, as famílias mais ricas ocupam as novas ruas e as ruas espaçosas da parte alta da cidade, enquanto as famílias mais pobres de todas as raças que atendem aos mais ricos costumam morar nas ruas. Em Nova Orleans, a pequena parte está localizada no centro e não há favelas monoculturais como em muitas outras cidades.

A história incomum de Nova Orleans, a rica composição étnica e cultural e a interação cultural resultante estabeleceram a base para o desenvolvimento e evolução de muitas tradições diferentes. A cidade é famosa por seus festivais, comida e música. Todos os grupos em New Orleans contribuíram para o ambiente musical muito ativo da cidade e para o desenvolvimento do jazz tradicional. 
A tradição africana de dança e percussão gravada em Nova Orleans é um exemplo famoso da mais antiga influência nacional significativa na música jazzística. $\mathrm{Na}$ metade do século XVIII, os escravos realizavam reuniões sociais em mercados especiais fora dos muros da cidade aos domingos. Depois de um tempo, eles a chamaram de Praça do Congo, famosa por sua dança africana e preservação da música e elementos culturais africanos.

Apesar da dança na Praça do Congo ter terminado antes da Guerra Civil, tradições musicais relacionadas surgiram na comunidade afro-americana na década de 1880. Os índios negros do carnaval têm uma relação espiritual com os índios americanos. No dia de carnaval, membros de gangues perambulavam por suas comunidades, tentando enfrentar outras gangues para mostrar que às vezes se tornam agressivos. A demonstração contou com tambores, gritos e respostas que se assemelham muito à música da África Ocidental e do Caribe.

Após a Guerra Civil, a música em Nova Orleans também foi influenciada pela música popular americana. As bandas de música estavam na moda no final da década de 1880 e as bandas musicais surgiram em todo o Estados Unidos. Estilos musicais semelhantes influenciados pelas tradições afro-americanas, como cakewalks e melodias de menestrel, também atraíram o interesse nacional.

Bandas musicais são muito populares em Nova Orleans e em outras partes do país. $\mathrm{Na}$ década de 1880, bandas de Nova Orleans como Excelsior e Onward geralmente consistiam de músicos formalmente treinados que liam partituras complexas para concertos, desfiles e bailes. As raízes do jazz em Nova Orleans foram nutridas pelos afro-americanos e tornou-se um fenômeno derivado de muitas comunidades e raças. $\mathrm{Na}$ década de 1890, as obras para piano chamadas ragtime e criaram uma sensação musical popular, e bandas de sopro começaram a complementar o repertório de marcha padrão com peças de ragtime.

Uma parceria especial foi estabelecida entre a orquestra de New Orleans e grupos de ajuda mútua e caridade. Sociedades de ajuda mútua e de caridade eram comuns entre muitos grupos étnicos em áreas urbanas no século XIX. Após a Guerra Civil, essas 
organizações tiveram um significado especial para os afro-americanos libertados com recursos econômicos limitados. O objetivo dessas sociedades é ajudar os doentes e enterrar funções importantes para os mortos, porque os negros são geralmente proibidos de ter acesso a serviços comerciais de saúde, seguro de vida e outros serviços.

Apesar de muitas organizações em Nova Orleans utilizarem bandas de música em desfiles, concertos, comícios políticos e funerários, grupos afro-americanos de ajuda mútua e de caridade têm suas próprias maneiras de expressar desfiles e desfiles fúnebres, e essa prática continua até hoje. Em suas atividades, celebridades da comunidade participaram de um animado desfile de dança.

Nova Orleans não se tornou apenas um importante porto marítimo e fluvial, mas também como um importante centro de entretenimento. Teatros legais, distribuidores de malabarismo, música e lojas de instrumentos musicais empregavam músicos na cidade. Os locais de entretenimento legal florescem dentro e ao redor dos distritos oficialmente aprovados, perto dos canais e das muralhas da cidade. Nas margens do Lago Pontchartrain, bandas competem por público em parques de diversões e resorts. Desfiles de quarteirões são comuns nas proximidades, e corredores comunitários e bares de esquina dançam quase todas as noites.

O povo de Nova Orleans nunca perdeu seu amor pela dança, e a maioria dos membros da banda de música da cidade também participava de bandas de dança. Acontecia que a equipe de uma banda de música de alto nível se sobrepunha à sua banda irmã. Bandas e bandas de dança usam instrumentos de cordas, como violino, guitarra e contrabaixo para reduzir o som de tubos de latão. Na virada do século, as bandas de dança de cordas eram populares em um ambiente mais educado. A música suja é conhecida como a dança mais requintada. É a base das bandas de cor crioula, como a John Robichaux Orchestra.

Mas em Nova Orleans, também há estilos de dança mais nativos. Na última década do século XIX, músicos não leitores que tocavam música não improvisada atraíram mais audiências de dança e desfile. Por exemplo, entre 1895 e 1900, o trompista 
Charles "Buddy" Bolden começou a incorporar blues improvisados e aumentou o ritmo da melodia dançante familiar.

Os instrumentos musicais e o desempenho da banda de sopro têm uma influência crescente na banda de dança, e a direção da banda mudou de instrumentos de corda para instrumentos de sopro. O que eventualmente se tornou a linha de frente padrão da banda de jazz de Nova Orleans foram trompas, clarinetes e trombones. Essas trompas, improvisadas ou disfarçadas de ragtime, produziram o acorde característico do jazz de Nova Orleans.

A maioria dos eventos em Nova Orleans era acompanhada por música e os músicos têm muitas oportunidades de emprego. Além de desfiles e bailes, a banda também participou de piqueniques, batatas fritas, partidos políticos, inaugurações de lojas, festas na grama, eventos esportivos, festas religiosas, casamentos e funerais. Os salões sociais do bairro geralmente são locais para banquetes e danças, alguns dos quais administrados por instituições de caridade e associações de autoajuda ou outras organizações civis. O jazz antigo foi encontrado nas comunidades de Nova Orleans e arredores, o que o tornou parte da vida dessas pessoas.

Jelly Roll Morton, estilista e compositor inovador de pianos, começou sua aventura fora de Nova Orleans em 1907. A Orquestra Crioula original foi uma importante banda inicial com Freddie Keppard. Ele deixou New Orleans e se mudou para Los Angeles em 1912 depois de um tour por Orpheum Theatre e atue em Chicago e Nova York. $\mathrm{Na}$ verdade, Chicago e Nova York se tornaram os principais mercados de jazz em Nova Orleans. A banda Tom Dixieland trocou New Orleans por Chicago em 1915, onde Nick LaRocca e outros membros da banda de jazz Dixieland foram em 1916.

Em 1917, a Dixieland Jazz Band original interrompeu seu primeiro registro comercial de jazz enquanto se apresentava em Nova York e recebeu uma recepção calorosa. A libertação de Victor foi um sucesso inesperado. De repente, o estilo jazz de Nova Orleans varreu o país. 
Com a nova demanda por jazz, oportunidades de emprego no norte persuadiram mais músicos a deixar New Orleans. Por exemplo, o clarinete Sidney Bechet deixou Chicago em 1917 e o flautista Joe King Oliver o seguiu dois anos depois. Em 1919, a banda de jazz Dixieland original se apresentou em Bechet na Inglaterra e na França. Sua música foi calorosamente recebida.

Em 1922, Louis Armstrong mudou-se para New Orleans, mas ao contrário de qualquer um de seus predecessores, sua atuação notável levou à revolução do jazz e substituiu os acordes de New Orleans com o desenvolvimento da arte do solista. $\mathrm{O}$ avanço tecnológico e a popularização das gravações de som divulgaram as inovações instrumentais e vocais de Armstrong e as tornaram famosas internacionalmente. Seus discos Hot Five e Hot Seven (1925-28), incluindo os trabalhos com Earl Hines, são muito populares e são marcos no desenvolvimento da música.

De modo que a música passou por uma série de rápidas mudanças estilísticas, os músicos e estilos musicais de Nova Orleans continuam a influenciar o jazz em todo o país. O jazz se tornou a música popular indiscutível nos Estados Unidos durante a era do swing das décadas de 1930 e 1940, e inovações posteriores (como o bebop na década de 40 e a vanguarda na década de 60) se afastando das tradições de Nova Orleans.

\subsection{SURGIMENTO DA MÚSICA BRASILEIRA}

Em termos de produção e atuação destacada de grandes compositores e intérpretes, a música popular brasileira ocupa posição de destaque no cenário internacional. No entanto, poucos envolvem a história da MPB, fato que pode perpetuar o desconhecimento desse importante patrimônio cultural, principalmente para a juventude. A especificação da MPB começou com Modinha e Lundu no século XVIII, e no início do século XX sinalizou a entrada de gêneros musicais europeus, como valsa e polca, e o surgimento de coros. No século XIX, as obras de Chiquinha Gonzaga, Ernesto Nazareth e Pixinguinha são patrimônios da música brasileira. A abertura da Casa Edison foi responsável pela prensagem dos primeiros discos de 78 rotações tupiniquins do século XX para o XXI, e de como a chegada dessa nova 
tecnologia mudaria nossa relação com a música. Registram o nascimento do samba ("Pelo telefone", DONGA, 1917) e as fusões realizadas por Noel Rosa, Cartola, ZéKeti, Nelson Cavaquinho e muitos outros nas décadas seguintes. Nos anos de 1930 e 1950, Era do Rádio, foi feito um mapeamento conduzido pelas rádios Nacional e Mayrink Veiga e protagonizada por artistas como Orlando Silva, Carmem Miranda, Ary Barroso, dentre outros. No final da década de 1950, a Bossa Nova teve uma mudança estética, e ao mesmo tempo assistiram nos anos 60 à Jovem Guarda, à época dos Festivais e ao Tropicalismo, movimentos que encontraram na televisão, aliado preferido da mídia. Do ponto de vista da política cultural, das canções antimilitares de Chico Buarque nos anos 70 ao rock de protesto brasileiro dos anos 80 , do Mangue Beat nos anos 90 ao ressurgimento da MPB, gêneros e movimentos musicais têm se desenvolvido constantemente nos últimos anos. Esses livros podem ser usados como um guia para organizar a história da MPB.

Como não se pode citar inventores, ficou consensual que Domingos Caldas Barbosa (1740-1800) é o principal promotor dos tipos Modinha e Lundu, cujo livro "Domingos Caldas Barbosa: O Poeta da Viola, Modinha e Lundu, José Ramos Tinhorão", o famoso historiador da MPB nos remete à segunda metade do século XVIII. Porém, graças aos esforços da comunidade musical, temos uma ideia de como Modinhas e Lundu chegam aos seus contemporâneos, a partir da pesquisa e reconstrução musical. Os instrumentos da época tentavam recriar os sons desses gêneros.

A chegada da família real em 1808 teve um impacto profundo em nossa vida cultural. Os imigrantes portugueses trouxeram instrumentos musicais como violões, bandolins e cavaquinho. Além disso, os instrumentos de sopro originalmente usados em bandas marciais ganharam um novo visual quando caíram nas mãos de músicos mestiços. Ao aplicar a execução desses instrumentos e da música europeia, valsas, polcas, schottiches, mazurcas aos ancestrais africanos, eles criaram um novo estilo, choro.

No final do século XIX século XX, o samba, cartão de visita musical do Brasil, oriundos das camadas mais baixas da população sofriam preconceito e transformação do ritmo sincopado do maxixe. O ponto de partida é a canção "Pelo telefone" (1917), de Ernesto dos Santos (Donga), mas Noel Rosa (1910-1937) foi o primeiro sambista a compor 
uma obra significativa e original. Noel levou o samba de morro para um campo mais amplo de distribuição, tecendo uma visão panorâmica dos costumes do Rio de Janeiro na década de 1930 e escrevendo clássicos como "Com que roupa? ", "Conversa de botequim" e "Gago apaixonado".

Em 1958, a Bossa Nova entrou em um período de euforia política e social no Brasil, impulsionada pela era da industrialização, pelo governo de Juscelino Kubitschek, apelidado de presidente da "bossa nova". A bossa nova, estilo consumido pela classe média alta, foi tematicamente inspirada na sedutora paisagem do Rio de Janeiro, e seu suporte musical foi influenciado pela harmonia do jazz e por elementos rítmicos emprestados do samba. Não por acaso, em 1962, no famoso show do Carnegie Hall, em Nova York, o público americano qualificou a Bossa Nova de "Brazilian Jazz".

A expertise de Antônio Carlos Jobim, aliada à poética letra de Vinicius de Moraes que na época foi considerado um dos maiores nomes da nossa tradição literária, e finalmente conquistou a finalização marcante das mudanças vocais de João Gilberto, resultando um produto de canções populares que conquistaram respeito de profissionais especializados. Referência em obras sobre a Bossa Nova, Ruy Castro, nos dá uma ideia dos exageros melodramáticos das canções da geração anterior. Embora os sambistas tradicionais frequentemente acusem o movimento iniciado por Tom, Vinicius e João Gilberto de elitista, e de muitos músicos da Bossa Nova terem se apropriado indevidamente composições da Velha Guarda ou aproveitando-se da ingenuidade destes e pagando quantias irrisórias a título de direitos autorais, o fato inelutável é que a Bossa Nova, pela excelência de sua produção, continua a representar o auge da produção de canções brasileiras.

\subsection{CONTEXTO HISTÓRICO DA BATERIA}

A bateria em sua formação completa é um instrumento recente, com cerca de 100 anos. A bateria completa está conectada ao surgimento do Jazz com raízes nas Marching Bands (bandas marciais) norte-americanas, e sua evolução tem uma ligação ao desenvolvimento do Jazz e do Rock que por consequência disso, se tornaram a principal referência para a pesquisa e produção de materiais didáticos para bateria. 
Houve inúmeros materiais e livros especializados do instrumento como o Modern Jazz Drumming de Jim Chapin. Seja por meio de cinemas, discos, livros ou métodos musicais, os americanos sempre tiveram forte influência na evolução da bateria brasileira, bateristas esse que buscavam informações num país que outrora atrasado em relação à música. No entanto, com a influência de bandas de jazz surgiram no Rio de Janeiro diversas bandas com arranjos e formações musicais diversas, o que levou ao surgimento de mais bateristas no cenário. Segundo Bolão (2003), o baterista Luciano Perrone é um dos representantes da percussão brasileira e considerado por muitos como o principal baterista brasileiro que surgiu da década de 50 até hoje.

Faleiros apud Paiva (2001) e Bolão (2003), apontam que:

a bateria da época consistia em uma caixa posta em uma cadeira, uma prancha suspensa em uma grade (para separar o músico do público) e um bumbo (às vezes batido com uma baqueta, às vezes com um pé) sem pedal.

Segundo a revista Carioca (apud BOLÃO, 2003), Perrone foi o primeiro a oferecer ao público um concerto de Bateria, que ocorreu na Rádio Cajuti, e o primeiro a gravar tal instrumento em discos. Além disso, foi o responsável pela gravação lendária de Aquarela do Brasil com Francisco Alves e o arranjador Radamés Gnattali. Tiveram outros grandes bateristas como Edson Machado, o primeiro a tocar samba com o prato de condução, e Milton Banana que tornou conhecido a levada rítmica da Bossa Nova através das gravações com Tom Jobim e João Gilberto que fizeram história e deixaram um legado na Bateria brasileira. A contribuição do jazz, dos métodos jazzísticos e de todo material teórico produzido por músicos de jazz ou escolas e institutos de jazz, trouxe uma revolução para a Bateria. De Gene Grupa até Buddy Rich, o desenvolvimento dos rudimentos aplicado ao estilo jazzístico por esses bateristas lendários, alavancou todo um século desde a criação da bateria completa. Somente em 1924 os brasileiros começaram a usar baterias completas, como a conhecemos hoje. Naquele ano, um grupo de jazz americano chamado Gordon Stretton Jazz Band (com Little Hester como cantor) fez uma turnê pela América do Sul. Em parceria com a Companhia de Revistas Bataclan de "Mistinguete", trouxe alguns mistérios pouco conhecidos sobre o instrumento musical banjo, que viria a 
substituir o violão nos conjuntos musicais, e a bateria, com bombo, caixa clara, pratos, cincerros, cocos e um monte de acessórios fixados em apenas uma peça, obtendo um sucesso inestimável. O percussionista brasileiro usava a caixa clara separada do bombo, o que fazia necessário dois instrumentistas.

A bossa nova foi incompreendida no seu início e criticada mesmo tendo músicos, compositores e cantores experientes. Para muitos na época, a bossa nova não passava de um produto da influência da música norte-americana, especialmente do jazz, sobre o samba. No entanto, em sua formação como compositor, influências como Debussy, Chopin e Ravel, Villa-Lobos, na esfera da música clássica, foram extremamente impactantes. Tom Jobim nunca negou uma forte influência do jazz no DNA da bossa nova. Segundo ele, trata-se de um caso de influência mutua onde os músicos de jazz foram seduzidos pelo ritmo sincopado e pelas harmonias sofisticadas da bossa nova, assim como a geração de músicos e compositores que a criou, na década de 50, foi influenciada tanto pelo jazz moderno de Shorty Rogers, Barney Kessell e Chet Baker como por grandes nomes da música americana tradicional como Gershwin, Cole Porter e Richard Rodgers.

Sendo assim, é possível entender como o jazz influenciou a musica brasileira, no caso, a bateria brasileira que também foi implementada ao repertório de standards do jazz, depois por cantores tradicionais como Ella Fitzgerald, Sarah Vaughan e músicos como Oscar Peterson e Joe Pass.

\subsection{IDEIAS E VARIAÇÕES DO SAMBA}

\section{CONSIDERAÇÕES FINAIS}

Durante todo o período da história da música, a bateria mesmo incompleta incialmente, desempenhou um papel fundamental, seja para fins práticos ou de entretenimento. Além disso, a música começou a partir dos instrumentos de percussão mais primitivos antes mesmo das primeiras civilizações. 
O jazz foi essencial na formação/construção da bateria. Com o surgimento do jazz em 1890, a bateria (drums set) tomou uma proporção evolutiva em cem anos que talvez em outro estilo não pudesse ser tão influenciado. É importante saber também que desde os tempos antigos, as cerimônias religiosas desempenharam um papel importante em influenciar as pessoas que passaram a utilizar instrumentos de percussão para fins militares, porque tocar bateria era uma das melhores maneiras de se comunicar com o povo.

Conforme a civilização progrediu, a percussão também foi se desenvolvendo. As raízes das peças comuns da bateria podem ser encontradas na Idade Média e no período renascentista europeu, mas algumas delas, como os pratos, existiram em sua mesma forma por centena de anos.

Portanto, com todo este breve histórico exposto, foi possível perceber uma rápida evolução influenciada pelos estilos de música em cada período da história, onde cada compositor, instrumentista ou inventor precisava daquela variedade de sons, o que gradativamente foi reduzindo o número de integrantes em instrumentos isolados, deixando de ter várias partes fracionadas para hoje estar resumido em um único instrumento, a bateria.

\section{REFERÊNCIAS}

BARSALINI, Leandro. Modos de execução da bateria no samba. 240 p. Tese (Doutorado em Música). Instituto de Artes, Universidade de Campinas, Campinas, 2014.

BOLÃO, Oscar. Batuque é um privilégio. Rio de Janeiro: Lumiar, 2003.

CANGANY, Harry. A Evolução dos "Sets" de Bateria. Revista Modern Drummer Brasil, n.1, p. 31-37. Junho, 1996.

FALLEIROS, Gustavo; BOLÃO, Oscar. História da bateria brasileira. Batera \& Percussão. Ed. Jazz, n. 31, março de 2000, p. 22-26. 
GIOIA, Ted. A História do Jazz. New York: Oxford University Press, 1997. viii, 471 pp.

GROUT, Donald J.; PALISCA, Claude V. História da Música Ocidental. Lisboa: Gradiva, 1994.

MALEY, Marshall. Drumset Fundamentals. In: Percussive Arts Society International Convention, 2000, Dallas, USA.

TINHORÃO, J. R. História social da música popular brasileira. São Paulo: Editora 34, 1998. 365 p.

Enviado: Maio, 2020.

Aprovado: Outubro, 2020. 